\title{
Identidade Cultural e o Corpo ${ }^{1}$ \\ Cultural Identity and the Body \\ La Identidad Cultural y el Cuerpo
}

\author{
Arnold Groh ${ }^{2}$ \\ Universidade Técnica de Berlim
}

\begin{abstract}
Resumo
O ser humano define a sua identidade principalmente pela forma como apresenta, desenha e estiliza o seu corpo. Ao fazê-lo, os indivíduos fazem declarações sobre a sua filiação para um contexto social. A globalização implica uma mudança de identidade entre os membros das culturas menos industrializadas, uma vez que estão expostos aos efeitos da dominação cultural. Para o indivíduo, essa exposição pode ser tanto mais forte quanto mais autônoma era sua cultura de origem antes do confronto. Há uma parcialidade de elementos culturais que estão sendo transferidos, de modo que a cultura industrializada tem um forte impacto em outras culturas. O consentimento global em relação aos padrões de comportamento, especialmente à autoapresentação corporal e aos estilos cognitivos relacionados, leva à obliteração do conhecimento tradicional, que está entrelaçado com o comportamento sobre o qual a identidade foi definida anteriormente. Os elementos culturais transferidos estão sendo utilizados para a construção de identidades pessoais globalmente padronizadas, em que os elementos relativos ao desenho visual do corpo humano são de grande relevância para a autodefinição. A perda de identidades diversas em favor da pertença à sociedade global provoca uma série de problemas que podem ser demonstrados em modelos funcionais. Esses modelos, por sua vez, podem apoiar o planeamento de estratégias de intervenção e o trabalho de resgate. Neste artigo, analisa-se o papel do corpo nos efeitos desestabilizadores da mudança cultural e discutem-se as possibilidades de intervenção.

Palavras-chave: globalização, corpo, identidade, cultura, indígenas, nudez, roupas, dominação
\end{abstract}

\begin{abstract}
Human beings define their identity primarily by the way they present, design and style their bodies. In doing so, individuals make statements about their affiliation to a social context. Globalisation implies a change of identity among the members of less industrialised cultures, as they are exposed to effects of cultural dominance. For the individual, this exposure can be the stronger, the more autonomous his or her culture of origin used to be before the confrontation. There is a bias of cultural elements that are being transferred, so that the industrialised culture has a strong impact on other cultures. Global consent with regard to behaviour patterns, especially to bodily self-presentation and the related cognitive styles, leads to the obliteration of traditional knowledge, which is interwoven with the behaviour upon which identity had been defined previously. The cultural elements transferred are being used for the construction of globally standardised personal identities, whereat elements concerning the visual design of the human body are of major relevance for defining the self. The loss of variegated identities in favour of belonging to the global society brings about a number of problems, which can be demonstrated in functional models. These models, in turn, may support the planning of interventional strategies and rescue work. In this article, the role of the body within the destabilising effects of cultural change are analysed, and chances for intervention are discussed. Keywords: globalisation, body, identity, culture, indigenous, nudity, clothes, dominance
\end{abstract}

\section{Resumen}

Los seres humanos definen su identidad principalmente por la forma en que presentan, diseñan y cultivan sus cuerpos. Al hacerlo, los individuos hacen declaraciones sobre sus afiliaciones en un contexto social. La globalización implica un cambio de identidad entre los miembros de culturas

\footnotetext{
${ }^{1}$ Este trabalho foi uma contribuição a "Bodies", a 8a Conferência Anual sobre Estudos de Cidadania (8th Annual Conference in Citizenship Studies), Center for the Study of Citizenship, Wayne State University, Detroit, MI (USA), 31 de março a 2 de abril de 2011. Tradução e revisão: Moema Augel, Universidade de Bielefeld, Alemanha; Sonia Grubits e Thiago Müller, Universidade Católica Dom Bosco, Campo Grande, MS, Brasil.

2 Endereço de contato: Straße des 17. Juni 135, Universidade Técnica de Berlim - Faculdade de Ciências Humanas. CEP 10623. Contato: +49-30-8227854, mobile +49-174-5717072 Berlin, Alemanha. E-mail: arnold.groh@tu-berlin.de
} 
menos industrializadas, ya que están expuestos a efectos de dominio cultural. Para el individuo, esta exposición puede ser más fuerte cuanto más autónoma fuera su cultura de origen, antes de la confrontación. Hay un sesgo de elementos culturales que se están transfiriendo, asi pues, la cultura industrializada tiene un gran impacto en otras culturas. Consentimiento global con respecto a patrones de comportamiento, especialmente a los de auto-presentación corporal y estilos cognitivos relacionados, conduce a la obliteración de los conocimientos tradicionales, que se entrelaza con el comportamiento sobre el cual la identidad había sido definida previamente. Los elementos culturales transferidos se utilizan para la construcción de identidades personales estandarizadas globalmente, donde elementos referentes al diseño visual del cuerpo humano son de gran importancia para definir el yo. La pérdida de identidades variadas en favor de la pertenencia a la sociedad global trae consigo una serie de problemas, que pueden ser demonstrados en modelos funcionales. A su vez, estos modelos, pueden apoyar la planificación de estrategias de intervención y trabajo de rescate. En este artículo se analiza el papel del cuerpo dentro de los efectos desestabilizadores del cambio cultural y se discuten posibilidades de intervención.

Palabras clave: globalización, cuerpo, identidad, cultura, indígena, desnudez, ropa, dominio

Nos contextos sociais, a identidade do sujeito é constituída por meio da autoexpressão, em particular pela apresentação visual e corporal do Eu (Goffman, 2009; Mummendey, 1990; Mummendey \& Bolten, 1985). Sendo assim, o outro se define pela forma que é percebido pelos demais. No nível semiótico, as culturas são caracterizadas por aglomerados de características consistentes que representam seus membros. Isso cria uma identidade coletiva (Snow, 2001). Ou seja, as pessoas percebem os membros de outras culturas como grupos; no processo, generalizações ocorrem - fenômeno cunhado por Mead (1934) como the generalized other, o Outro generalizado.

Em espaços não globalizados, as afiliações culturais das pessoas geralmente são perceptíveis, sobretudo visualmente, e é dependente do grau de dominância a extensão da influência cultural. Se existe tal agente, então há uma direção principal da adoção de elementos culturais constitutivos da identidade, de tal maneira, que, principalmente os dominados, adotam alguns traços dos dominantes, e não o contrário; desse modo, os dominados tentam aliviar seu sentimento de inferioridade, no sentido da teoria da autossuplementação simbólica (Wicklund \& Gollwitzer, 1982). A adoção de roupas, por exemplo, leva a modificações de graves consequências das identidades dos Dominados, especialmente.

No curso subsequente, isso leva à perda da identidade cultural e, depois, à desestabilização e ao colapso dos sistemas sociais afetados. Em princípio, os dominantes podem impedir isso, por meio da inversão do processo no encontro cultural. Em termos concretos, adaptando sua aparência externa à apresentação tradicional do corpo, as pessoas globalizadas demonstram respeito e aceitação, evitando assim a perda da cultura indígena (Groh, 2018). A partir de uma perspectiva racional, este é o comportamento apropriado, porque é analógico, paralelo e simétrico à adaptação dos indígenas à cultura dos espaços globalizadas.

Com culturas indígenas já desestabilizadas, a orientação na aparência tradicional também suporta o exercício do direito de revitalizar, de acordo com o art. 11 da Declaração das Nações Indígenas sobre os Direitos dos Povos Indígenas (2007). No entanto a adaptação razoável, lógica e necessária dos dominantes a contextos indígenas é, muitas vezes, bloqueada por padrões de comportamento irracionais dos globalizados. Essa característica é particularmente evidente em países de clima tropical, onde a cobertura do corpo não é uma resposta adequada às condições climáticas- aparentemente são mantidos os comportamentos que foram importados da Europa. O comportamento de acobertar o corpo é um fenômeno que precisa 
de pesquisa psicológica direcionada, pois investigações dinâmicas (Hill, 1996; West, 2017) mostram que o estado indígena indisfarçável se correlaciona com seu bem-estar psicológico e comportamento pró-social.

A indústria cultural não aceita a aparência física tradicional de pessoas indígenas, embora essas culturas sejam a maioria - das $7.000^{3}$ existentes no planeta, aproximadamente, de 4.000 a 5.000 são consideradas indígenas, das quais cerca de 2.000 vivem de maneira tradicional -, elas permanecem amplamente ignoradas pela cultura dominante. Não há aceitação mútua de estilos de vida. Muito pelo contrário, os padrões são ditados pela indústria ultural. Com sua aparência física idiossincrática que, em regiões tropicais, pode significar nudez muitas vezes, os indígenas dificilmente teriam uma chance de serem reconhecidos como cidadãos ou então de receber passaporte.

A situação contrasta fortemente com algumas reivindicações básicas da cultura global. As Nações Unidas, a partir da Declaração das Nações Unidas sobre os Direitos dos Povos Indígenas (2007), claramente exige a aceitação dos estilos de vida indígena. Apesar dessa proteção, a cultura dominante está prestes a extinguir qualquer lembrança do que foi característico da espécie humana durante a maior parte de sua história.

Devemos analisar a questão pela premissa de situações onde há contato específico entre a cultura dominante e a dominada, ou seja, situações em que os problemas acontecem, para então considerarmos intervenções possíveis e eficazes.

\section{Descrição da Situação}

\section{Direito Internacional}

Um passo muito importante foi dado pelas Nações Unidas com a Declaração sobre os Direitos dos Povos Indígenas, aprovada em assembleia geral em 2007. Desde então, isso faz parte da Lei Internacional e deve ser respeitado em todo o mundo. De acordo com a Declaração, os povos indígenas têm direito à autodeterminação conforme consta no art. 3으, suas culturas devem ser protegidas, determinação dos art. 8o e 31, possuem direito a revitalizar suas tradições segundo o art. 11 e ter sistemas educacionais próprios, estabelecido no art. 14.

Os Estados estabelecerão mecanismos eficazes para a prevenção e a reparação de: Todo ato que tenha por objetivo ou consequência privar os povos e as pessoas indígenas de sua integridade como povos distintos ou de seus valores culturais ou de sua identidade étnica (Artigo 8, 2 a).

Por fazermos parte da cultura dominante, devemos nos preocupar em compreender os mecanismos de qualquer ação que possa, eventualmente, surtir o efeito de desestabilizar qualquer cultura indígena e lutar para evitar tais ações.

Uma das primeiras conferências das Nações Unidas teve como ponto central a Liberdade de Informação ${ }^{4}$. Esse tópico é bastante importante para a pragmática de assegurar as culturas tradicionais. Se alguns conservadores clamassem pelo isolamento de culturas tradi-

\footnotetext{
${ }^{3}$ Com base na língua como parâmetro; ver www.ethnologue.org para dados recentes.

${ }^{4}$ Conferência da Organização das Nações Unidas sobre a Liberdade da Informação, ocorrida em Genebra, de 23 de março a 21 de abril de 1948.
} 
cionais, isso seria uma violação da liberdade de informação e de outros direitos básicos, porque as pessoas seriam incapacitadas da possibilidade de se comunicarem. Esse aspecto deve ser especialmente levado em consideração devido às atividades missionárias: curiosamente, uma proibição de tais atividades implicaria uma forma de controle do pensamento. Aqueles que proíbem o proselitismo também impedem implicitamente certas ideias de atingirem as pessoas envolvidas, decidindo, assim, o que é permitido a eles pensar e o que eles sequer devem saber. Porém um efeito resultante da liberdade de informação é a liberdade para decidir. Isso apenas pode ser assegurado se todas as alternativas forem conhecidas.

Quanto mais informação disponível, maior é a liberdade de escolha. Contudo, quando se trata de fornecer qualquer informação de uma cultura a outra, o respeito e a aceitação mútuos são de suma importância. Se um lado dominar o outro, efeitos sociocognitivos específicos contra-atacam a liberdade de escolha. Sem o respeito mútuo, a decisão de uma pessoa, tomada sob a dominância cultural, não pode ser considerada livre, pois seria apenas uma reação a essa dominância na tentativa de evitar uma sensação de inferioridade.

\section{Identidade Cultural}

As culturas podem ser definidas de acordo com a articulação de seus signos, ou seja, elementos culturais que representam sua afiliação por meio de comunicação (Posner, 1989). Entende-se que a linguagem cria uma identidade cultural, sendo usada intencionalmente para afirmar a identidade (Kummer, 1990). O tipo de alimentação também constitui identidade cultural (Gibbons, 1992). Entretanto ambas não são permanentemente perceptíveis. Por outro lado, a autoapresentação visual se constitui como uma declaração permanente de identidade cultural.

Ao passo que a cultura global exerce seu domínio sobre as culturas indígenas, as normas de cobertura do corpo são transferidas para as culturas tradicionais. Com a forma globalizada de autoapresentação, as identidades indígenas anteriores são perdidas. Este é o mecanismo central da destruição das culturas tradicionais, porque, como sabemos, a partir de pesquisas sobre Social Embodiment, o que acontece com o corpo tem um impacto sobre o pensamento, atitudes, emoções, motivações e funções psicológicas em geral e estado mental (Gallagher, 2005).

Existem alguns exemplos de culturas que têm contato com outras sem perderem suas tradições. Não exclusivamente o contato que desestabiliza e, eventualmente, destrói uma cultura, mas sim a forma com a qual esse contato ocorre. Enquanto a dominação cultural exerce um efeito destrutivo sobre a cultura dominada, o respeito mútuo assegura a sustentabilidade cultural. Tanto a dominação, quanto o respeito, são percebidos por meio da comunicação. Uma vez que as culturas indígenas em geral possuem uma linguagem particular, não verbal, a comunicação visual passa ter um papel de destaque. Para compreender esse destaque, faz-se necessário entender como a identidade é constituída e comunicada, primeiramente.

Apenas as manifestações externas de identidade, e não as internas, são relevantes dentro do contexto social. Independente da razão, se alguém tivesse a estranha ideia de que era um alienígena, essa pessoa teria uma identidade bastante incomum. No entanto, se a 
pessoa guardasse a ideia para si mesma, sua identidade se tornaria irrelevante para o contexto social. Somente o que é percebido pelos outros importa a eles. Sendo assim, as manifestações externas são importantes. É por meio da autoapresentação que a pessoa define sua identidade.

As pessoas podem se apresentar de maneiras diferentes. A identidade manifestada externamente é maleável. Um indígena que se muda para uma cidade geralmente integra-se a esse novo contexto, comunicando uma identidade adaptada por meio de roupas e submissão a padrões modernos de comunicação visual em termos de autoapresentação.

\section{Dominação Cultural}

No curso histórico, a gênese da dominância cultural pode ser explicada pelo número relativamente alto de sínteses estratégicas culturais acumuladas aos grupos dominados que são percebidas subjetivamente como efetivas (Groh, 1993a, b). Em situações concretas, efeitos bem conhecidos são adicionados, tais como subordinação sob autoridade (Milgram, 1974) ou conformidade de grupo (Asch, 1951).

A dominação exercida pela cultura global sobre as culturas indígenas pode ser facilmente percebida se examinarmos contatos interculturais ocorridos em território indígena. Em geral, os dominadores não se integram à cultura indígena da mesma forma que as culturas indígenas se integram aos contextos globalizados.

Em territórios indígenas, invasores globalizados geralmente não se despem, em vez disso, sinalizam sua superioridade apresentando-se com sinais da cultura industrial. É a essa pressão social da dominação cultural a que os povos indígenas estão expostos, o que resulta em uma sensação de inferioridade por parte dos índios.

Então, eles tentam se desvencilhar dessa inferioridade percebida modificando sua manifestação identitária exterior. Em décadas passadas, cada vez mais índios passaram a usar roupas, mas não porque gostavam. Na realidade, se formos comparar o uso de roupas em florestas quentes e úmidas com a nudez natural que sempre foi prevalente durante os milênios passados, a forma natural de autoapresentação é a mais confortável.

Nesses ambientes, as roupas quase que instantaneamente umedecem com o suor, devido ao ambiente propício para proliferação de germes e dermatófitos- muitas vezes levando a problemas dermatológicos graves. A imitação de padrões de comportamento globalizado, como cobrir o corpo, é irracional; isso pode, no entanto, ser explicado pelos mecanismos psicológicos da dominação cultural (Groh, 2006).

Em suma, quando importados em um contexto indígena, os elementos culturais da cultura dominante relevantes para a autodefinição podem eliminar a identidade indígena e substitui-la por outra mais globalizada (Groh, 2007). Com uma identidade global, os índios irão, por outro lado, abandonar o comportamento tradicional - inclusive o da perpetuação de conhecimento específico que é passado de geração em geração.

Essa influência desestabilizadora, exercida por culturas dominantes a culturas tradicionais, contribui, em uma sequência de acontecimentos, para os complexos problemas que recentemente começaram a ameaçar o planeta, como: o desmatamento, a perda de espécies, a desertificação e as mudanças climáticas. 


\section{Neutralizando a Desestabilização}

Quando integrantes da cultura industrial vão a territórios de cultura indígena, elas podem neutralizar os processos destrutivos e inclusive contribuir para a re-estabilização dessas culturas. Se a pessoa se integrar à cultura enquanto lá estiver, isso encorajaria os índios a não se sentirem envergonhados de sua aparência tradicional. Ao apresentar-se dessa maneira, a pessoa comunica aceitação e respeito em relação a essa cultura ${ }^{5}$ - incidentalmente, o mesmo se aplica e se espera dos índios que adentrem ao contexto globalizado.

Contudo adaptar-se à aparência tradicional é o aspecto mais óbvio - e mais importante - da integração. Um exemplo de outro aspecto comportamental integrador seria o canto. Culturas indígenas geralmente têm um amplo repertório de canções. No entanto não seria apropriado apenas pedir aos índios para cantarem. Em nossa própria área de pesquisa, tentamos e testamos a noção de que devêssemos cantar algumas canções ${ }^{6}$. É muito provável que os índios respondam com suas próprias canções. Esta é uma aplicação prática do princípio da reciprocidade. Ele permite que as duas partes se comuniquem com dignidade.

Se você deseja ouvir os índios cantarem, então deve cantar. Se deseja ver os índios em seu estado natural de nudez, precisa ficar nu. Qualquer outra combinação seria assimétrica, e o povo indígena seria privado de sua dignidade. Se os visitantes estivessem vestidos, olhando para os índios nus, isso seria semelhante a um zoológico etnológico. Se eles pedissem que os índios dançassem, assemelhar-se-ia a um circo. A abordagem minimamente invasiva, do contrário, reforça a confiança e cria uma situação de respeito mútuo.

\section{Um Exemplo Prático: Turismo como Ameaça à Cultura7}

O turismo é uma das maiores indústrias do mundo; seu potencial econômico dificilmente pode ser superestimado. Como sistema socioeconômico, ele reage de maneira bastante sensível a mudanças contextuais, por exemplo: se Mombasa Beach adaptar demais suas características a outros destinos globalizados, isso pode rapidamente resultar em uma queda no número de reservas. Até recentemente, o valor cultural para os turistas no Quênia era acrescentado por meio de safaris de jipe de meio-dia a vilarejos locais, onde eles visitavam as populações indígenas. Mas essa forma de utilizar recursos locais mostrou-se insustentável. Assim como ocorre em muitos outros lugares, a cultura típica deteriorou após poucos anos de contato com turistas. Antes autênticas, as vilas logo tornaram-se favelas e perderam, assim, seus atrativos. Os agentes de turismo então passaram a reagendar excursões a vilarejos mais distantes, mesmo sabendo que isso desencadearia os mesmos processos de deterioração. Enquanto isso, excursões assim são feitas de avião no Quênia.

Nesse processo de perda cultural, o papel da indústria do turismo é um tanto paradoxal. Por um lado, ela depende da cultura como recurso; já por outro, ela infiltra elementos culturais externos nas culturas locais. Esses elementos dominantes não apenas eliminam e

\footnotetext{
${ }^{5}$ Aspectos relevantes à área de pesquisa, como os discutidos neste trabalho, foram apresentados pelo autor na 6a Conferência Africana sobre Psicoterapia ( $6^{\text {th }}$ African Conference on Psychotherapy), em Kampala, Uganda, de 14 a 16 de dezembro de 2010.

${ }^{6}$ Por razões de reforço de confiança, é útil quando os pesquisadores são um casal. Se o grupo de pesquisadores for maior, o número de homens em geral não deve exceder o de mulheres, uma vez que a poligamia é comum entre as culturas indígenas.

${ }^{7}$ Consulte Groh $(2012,2005)$ para aspectos relevantes ao turismo, conforme discutido neste trabalho.
} 
substituem os elementos culturais tradicionais, eles também se mostram incompatíveis com aquele contexto em particular que passaram a ocupar.

Nas situações de contato entre a cultura dominante e a dominada, a relação entre as partes é bastante assimétrica. Em uma situação típica de contato, quando os turistas visitam um vilarejo indígena, estes vêm como consumidores; sua percepção quanto aos seus direitos está baseada no fato de que eles pagaram pela viagem. Para os turistas, os indígenas são meros objetos, cuja autoapresentação é meramente encenada nesse arranjo. Em tal situação, não se trata realmente de contato pessoal, mas sim de uma negociação.

Enquanto os visitantes vierem como os representantes dominadores da globalização, aqueles que não se integram à cultura indígena, haverá um nível invasivo alto que provocará os processos de desestabilização. No momento atual da história, a mobilidade neste planeta está como nunca esteve antes. Porém essa mobilidade também está assimetricamente distribuída. No mundo de hoje, quanto maior a mobilidade das pessoas, mais industrializada é sua experiência. Ao contrário, os povos mais tradicionais têm menos acesso a meios de transporte eficazes. O transporte aéreo cresceu enormemente nos últimos anos, o que permitiu a mochileiros, em grupo ou individualmente, chegarem a lugares exóticos e interferir nas culturas tradicionais.

\section{Processos Sociocognitivos}

Paradoxalmente, a rotulação de uma vila tradicional, como sendo especialmente autêntica, reforça a destruição dessa cultura. Esse comportamento coletivo irracional de turistas está profundamente arraigado em um problema identitário da cultura industrial. Os viajantes carregam consigo os conflitos internos de sua própria cultura para dentro das culturas indígenas. Isso não leva a nenhuma solução desse conflito; é apenas um ato simbólico que pode exacerbar ainda mais o problema.

Uma das forças motrizes dos interesses dos viajantes em culturas indígenas exóticas e arcaicas é a busca por sua própria origem. Há um consenso de que, em tempos idos, nossa própria cultura foi similar às culturas indígenas atuais. Portanto visitar povos indígenas é uma busca por raízes e fundamentos de nossa própria identidade. Como o passado mítico é idealizado, trata-se também de uma busca pelo paraíso perdido. O Jardim do Éden parece, assim, acessível - ou quase: a projeção de nosso próprio passado cultural sobre as culturas indígenas está amalgamada com a ideia de um paraíso tropical como sendo o mundo ideal. Mead (1928) contribuiu muito para o estabelecimento desse mito até mesmo nas ciências sociais. Sua conceituação, após ser cultivada durante várias décadas, foi então refutada por Freeman (1983).

A identidade dos integrantes da cultura industrial contrasta bastante com a identidade indígena, e os visitantes se veem muito diferentes das pessoas que vivem tradicionalmente. Os turistas entendem que sua cultura abandonou, há muito tempo, as condições nas quais os povos indígenas são observados. À medida que os visitantes se identificam com sua própria cultura, eles percebem essa mudança de um estado "primitivo" para outro "melhor" como uma progressão ativa, baseada na decisão coletiva. O julgamento comparativo implícito pode ser explicado cognitivamente como uma justificativa para o progresso irreversível. Do contrário, seria contraditório retornar para casa após a visita e continuar a vida no ambiente 
globalizado. Tanto coletivamente como individualmente, os visitantes estão comprometidos com o progresso da cultura industrial.

Existe uma ação recíproca entre mitos da memória coletiva e a experiência real da outra cultura. Ambas são complementares, de maneira que os mitos preenchem os espaços entre o conhecimento fragmentado obtido com a realidade 8 . Se realmente contradisser os mitos, a percepção poderá até certo ponto ser suprimida ou reformulada para manter a imagem projetada. As expectativas que resultam desses preconceitos filtram as percepções e influenciam a compreensão. A filtragem cabe aos elementos culturais desconhecidos, que permanecem ininteligíveis e, portanto, são apagados (Bartlett, 1932).

Já a distorção da percepção ocorre como resultado de interpretações erradas em decorrência da falta de conhecimento sobre a outra cultura. Nas teorias culturais do início do século XX (Freud, 1913; Mead, 1928), o equívoco mais comum é a associação da nudez indígena com a sexualidade. Ao ser dissonante dos valores da cultura industrial, essa interpretação errada leva a medidas corretivas supostamente necessárias, que atuam desde interferências individuais por turistas que dão roupas aos índios até a informações errôneas na cobertura midiática (que infringem os Artigos 15ㅇ e 16으 da Declaração das Nações Unidas sobre os Direitos dos Povos Indígenas), ao cobrirem índios, uma vez que a nudez é considerada inaceitável, passando por intervenções em larga escala na esfera política.

\section{A Valorização da Cultura Dominante Sobre as Indígenas}

No campo bem estabelecido da dissonância cognitiva (Festinger, 1957), há uma linha de pesquisa sobre Justificativa do Esforço. Essa área possui grande expressividade, devido ao elevado investimento de tempo, dinheiro e outros elementos quando os integrantes da indústria cultural viajam para ver uma cultura indígena, e sentem necessidade de justificar a experiência como "boa", "útil" e de alguma maneira "positiva". Sistematicamente, há uma repercussão no fato de que, após um breve encontro, os visitantes retornam para casa com suas avaliações sobre a cultura indígena.

Consciente ou inconscientemente, os turistas assumem a posição de que sua vida em casa deve ser "melhor" e que a cultura indígena "não vale a pena" ser preservada. Quando uma pessoa percebe uma conexão entre sua decisão e as consequências, então essa decisão torna-se bastante resistente a mudanças. A decisão a favor da cultura globalizada prevalece e só é revista se algum argumento dissonante for irrefutável (Frey, 1981). Em geral, as pessoas se esforçam para reduzir dissonâncias durante o tempo que for possível, desvalorizando os argumentos divergentes.

Além disso, se examinarmos a situação de encontro durante a visita de pessoas globalizadas a um povoado indígena, sob a perspectiva da Teoria de Campo (Lewin, 1951), a compreensão dos visitantes, assim como seu comportamento manifesto, será determinada por seu papel de representantes da cultura industrial, e essa percepção de pertencimento determina fundamentalmente a avaliação da cultura indígena.

\footnotetext{
${ }^{8}$ Consulte Kohonen (1988) e Palm (1982) para apresentação da complementação cognitiva. Cf. Lévi-Strauss (1973) para a função dos mitos.
} 


\section{Efeitos Cognitivos da Visita de Culturas Dominantes a Culturas Indígenas}

As percepções e atribuições mútuas acompanham as atribuições de prestígio. Essas avaliações são baseadas em inferências relacionadas à eficácia e implicam comparações entre as culturas envolvidas, bem como em preferências consensuais destacadas por essas comparações. Entre as pessoas que participam de um encontro de culturas, a visão de que uma das culturas é superior e a outra é inferior irá prevalecer. De fato, a cultura dominante será vista como mais atrativa do que a dominada.

Temos que destacar claramente que essa noção de prestígio e atratividade é construída com base em interpretações preconceituosas de percepções fragmentadas, suposições e projeções arbitrárias. Mesmo as atribuições de eficiência são feitas de posições subjetivas; se, por exemplo, um morador de uma floresta tropical consegue uma motosserra, ele pode entender que é bastante eficaz cortar muitas árvores em um curto período e ganhar muito dinheiro vendendo a madeira. Embora, de uma perspectiva menos subjetiva, tal dano ao ecossistema não seja nada eficaz.

Enquanto os dominantes aproveitam a visita como consumidores, os dominados são expostos a uma enorme pressão psicológica. É natural que uma pessoa queira fugir de uma situação tão desconfortável como a de ser o oprimido. Alguns índios podem supor que a longo prazo possa ser vantajoso trocar de lado e juntar-se à cultura global. Então, eles deixariam de ser considerados "primitivos" e "atrasados". Contudo, se desejarem realizar tal mudança, eles terão de lidar com as dissonâncias, apagando aspectos de se tornar parte da cultura que tem o papel principal na destruição do planeta, bem como outros pensamentos críticos. As percepções dissonantes que eventualmente surjam seriam reduzidas, caso houvesse esforços para convencer ainda mais seus companheiros índios a abandonarem sua cultura tradicional, ampliando dessa maneira ainda mais a cultura industrial padrão global. No entanto reflexões entre sistemas seriam um tanto dissonantes a qualquer decisão a favor da cultura industrial. Para aqueles que tomam tal decisão, é mais conveniente não ponderar a expectativa de vida indígena comparada às casualidades decorrentes das emissões industriais, trânsito, guerras e outras mortes intencionais; ou a rápida perda de espécies, desertificação e mudanças climáticas comparadas ao uso sustentável da natureza feito pelos povos indígenas.

Da mesma maneira, seria mais conveniente não considerar os efeitos do estresse da cultura industrial sobre o bem-estar psicológico. Frey (1981) descreveu estratégias para evitar informações dissonantes de modo a prevenir qualquer desestabilização da posição de cada um; as pessoas também seletivamente se expõem ao input cognitivo, afirmando uma decisão que tomaram. As pessoas expostas à desfasamento cognitivo somente se submetem caso não consigam fugir de argumentos convincentes (West \& Wicklund, 1985). Se elas podem se esquivar, elas mantêm suas posições e diminuem a dissonância. Em razão do desequilíbrio da dominação cultural, a decisão dos membros da cultura industrial de permanecerem com sua cultura é facilitada, bem como a tentativa dos índios de migraram para a cultura industrial. Esse resultado é chamado de globalização. 


\section{Aspectos Sistêmicos}

Alguém pode perguntar: qual o problema? As pessoas se modernizam, ficam "civilizadas", e daí? Mas até o fato de fazer essa pergunta reflete os mecanismos de ignorância dos aspectos críticos. Em uma avaliação superficial, o comportamento da cultura industrial, quando massivamente maltrata este planeta, é irracional. Portanto a popularidade da cultura industrial, manifestada na globalização, é irracional da mesma forma. Porém esses padrões irracionais são determinados por múltiplos fatores, sobretudo pelo fenômeno sociopsicológico. Nesse mecanismo, é crucial que as pessoas associem a cultura industrial com a valorização social, em vez de refletirem sobre a razoabilidade a longo prazo.

Se nos permitirmos uma reflexão inconveniente, podemos ser capazes de identificar algumas inter-relações. Por exemplo, culturas indígenas em florestas tropicais constituem sistemas com seu próprio ambiente natural, que podem ser estáveis ao longo de milênios, contanto que não sejam perturbados por elementos externos. Florestas tropicais intactas produzem consideravelmente mais alimento para seres humanos do que poderia ser produzido pela agricultura em uma área equivalente ${ }^{9}$. Portanto intervenções para estabelecer agricultura nessas regiões é um tanto irracional.

Também temos ciência dos efeitos da destruição das florestas tropicais no clima global. Sendo assim, faz sentido considerarmos possíveis contramedidas relacionadas a esses problemas interconectados. Em particular, o aspecto de desestabilizar culturas até então intactas, dando início, assim, a uma cadeia causal, convites para a prevenção ou, no mínimo, a minimização do ato invasivo. Na verdade, o contato com culturas indígenas deveria exigir treinamento e qualificação específicos. Mas, como a mobilidade e o turismo a longas distâncias são parte do mercado global, tal obrigação dificilmente seria estabelecida. Em vez disso, faz sentido discutirmos relações causais para sensibilizar o mundo globalizado em relação ao respeito a culturas ameaçadas e despertar a atenção para esses problemas.

De maneira paradoxal, povos indígenas são considerados consumíveis, enquanto que, ao mesmo tempo, sua existência é quase negada pela cultura industrial. A percepção que se tem dos povos indígenas está geralmente restrita a momentos de diversão, como viagens de férias, fotos, filmes, restaurantes exóticos, artesanatos étnicos e de aeroportos e outras lembranças. Essa realidade ignorada ainda abrange milhares de culturas neste planeta.

Se os processos de globalização continuarem existindo como acontece hoje, então podemos esperar que apenas dez por cento das culturas vivas hoje sobrevivam ao século XXI; cerca de 2.000 culturas estão seriamente sob ameaça existencial ${ }^{10}$. Essas culturas são geralmente taxadas de "primitivas", "atrasadas", "subdesenvolvidas" ou até de "selvagens nus" por parte da cultura industrial. No discurso acadêmico, podemos encontrar paráfrases equivalentes, embora politicamente corretas.

Alguns representantes do Primeiro Mundo ficam até surpresos quando aprendem sobre pessoas que vivem fora do mundo industrializado, que vivem em ecossistemas naturais de maneira sustentável e que usam pouca ou nenhuma roupa. Na verdade, o padrão comportamental da cultura industrial, tanto por parte de seus indivíduos quanto por parte de suas políticas praticadas, está involuntariamente envolvido na remoção de todas essas culturas

\footnotetext{
${ }^{9}$ Uhl, C. (1991). Entrevista: Christopher Uhl em Heine.

${ }^{10}$ Veja www.worldwatch.org para números atuais.
} 
tradicionais da face da terra. A cultura industrial de forma bastante conveniente aparentemente se esquece de que outras culturas vivem de uma maneira que é típica da humanidade em milênios de sua existência. Estamos eliminando nosso passado histórico.

A lei brasileira distingue, por exemplo, índios "civilizados" de índios "selvagens". Apenas índios "civilizados", que se adaptaram à cultura industrial vestindo-se, usando dinheiro, vivendo em assentamentos modernos, falando a língua oficial, tendo emprego e usando meios de transporte modernos, são tratados como iguais por outros cidadãos. Do contrário, os "selvagens" são privados de seus direitos e tratados como incapazes pelo governo. A aculturação é vista como um processo normal; o desequilíbrio da dominância cultural, da pressão social e dos fatores psicológicos por trás dela é considerado irrelevante e inconsequente. Não é apenas aceita, existem ainda políticas específicas para que os índios se tornem cada vez mais brasileiros "civilizados", sem o arrependimento de que o mundo então será um lugar mais pobre e que a destruição avançará sem resistência, em todos os sentidos.

Reconhecidamente, eliminar outras culturas não é nada novo. Mas com o início da expansão europeia, há cerca de 500 anos, isso aumentou. E como há novos meios tecnológicos, a aceleração é quase exponencial. No século XX, entramos em uma fase de perda cultural rápida. Enquanto nos séculos passados relativamente poucos navegadores sujeitavam outros povos ao engano e à exploração, hoje o esgotamento de outras culturas aumenta à medida que cresce a mobilidade da cultura industrial. Quantos aviões estão em voos longos neste momento? Quantos passageiros estão sendo transportados de uma parte do mundo para outra nesse instante? Quantos são ao longo do ano? Que efeito tem a presença física das pessoas, que podem ser móveis, sobre milhões de outras com quem estabelecem contato? Como elas são percebidas?

Conforme apontado anteriormente, a percepção é um aspecto-chave quando se trata de mudança cultural. As pessoas veem umas às outras de maneiras muito diferentes, como o dominador olhando para o dominado ou vice-versa. A partir de uma perspectiva indígena, os dominantes não são vistos como consumíveis, ou humanos, cuja existência pode ser totalmente ignorada sempre que alguém se cansa deles.

\section{Efeitos da Dominação Cultural}

A perda das culturas é provocada durante os encontros reais entre dominadores e dominados. Nessas situações, a interação acontece de uma forma bem assimétrica. Enquanto houver uma enxurrada de elementos culturais dominantes varrendo os elementos da cultura dos dominados, apenas alguns poucos elementos são transferidos na direção contrária. Estrategicamente, a cultura dominante escolhe apenas aqueles elementos que podem oferecer alguma vantagem no futuro, enquanto que a adoção irrestrita dos elementos da cultura dominante pelos dominados é movida pela expectativa de redução na sensação de inferioridade.

Sem qualquer contato entre a cultura A e a cultura B, a mudança cultural não seria provocada em nenhum dos lados. Ainda assim, dogmáticos políticos alegam que as culturas indígenas de qualquer forma se "desenvolveriam", mais cedo ou mais tarde, na direção de maneiras de se viver como na cultura industrial. Porém, por serem tão "atrasados", eles precisariam de algum auxílio para eventualmente se tornarem parecidos conosco. 
Contudo o conceito de desenvolvimento é inutilizável para o fenômeno da cultura, pois sugeriria processos específicos, os quais existem no campo da biologia, mas não podem ser alegados para sistemas sociais. Na realidade, esse conceito tem a função de um dogma político, por meio do qual se justificam as intervenções em outras culturas. Políticas de "auxílio ao desenvolvimento" são evidentemente orientadas ao próprio modo de vida da pessoa. O uso inquestionável desses termos também tem um impacto no comportamento dos visitantes às comunidades indígenas. Deixar com elas elementos culturais formadores de identidade, como camisetas, na selva causa um efeito desestabilizador nos sistemas culturais indígenas.

Assim como outros aspectos do encontro, a influência mútua também é bastante assimétrica: em razão de seu histórico cultural dominante, o exemplo do visitante define a agenda para os objetivos globalizados. Para os indígenas, o encontro turístico tem consequências sérias, enquanto que para os visitantes é apenas um episódio, uma experiência interessante. Pelo aumento da mobilidade da cultura industrial, o número de situações de contato também tem crescido. Como resultado dessas interações, o processo de aumento da miséria vem ampliando-se em cada vez mais lugares, e a única resposta da cultura dominante a isso é incitar as culturas dominadas a desistirem de seu modo de viver tradicional e estável até o momento, sem fornecer qualquer substituição sustentável para essa perda.

A desestabilização é amplamente ignorada pela cultura dominante, e seus representantes em geral não creem que exercem alguma influência, independentemente de sua intenção, uma vez que é impossível não agir, já que qualquer comportamento perceptível é um ato de comunicação. Desde que nem a aceitação nem o respeito sejam sinalizados, a influência, que o dominador exerce sobre o dominado, é uma enorme pressão social e psicológica, da qual os índios tentarão escapar e acabarão por desistirem de sua cultura.

\section{Destruição da Identidade é Destruição Cultural}

As culturas estão sendo destruídas em razão da modificação das identidades de seus membros. Ao adotarem os elementos da cultura dominante, os indígenas se redefinem e se atribuem a cultura global. Nesse processo, elementos culturais indígenas, tradicionais e antigos, estão sendo eliminados, o que significa que informações culturalmente específicas estão se perdendo nesse processo de globalização. Entre todas as ações comunicativas de definição de identidade, os elementos de autoapresentação relacionados ao corpo são os mais importantes. Comparada à linguagem, alimentação ou moradia, a relação com o corpo implica uma referência constante ao individual. Dessa maneira, elementos culturais relacionados ao corpo são particularmente relevantes para que a pessoa defina a sua identidade (Burris \& Rempel, 2004).

Dentro dos processos assimétricos de compreensão mútua e transferência de elementos culturais entre o dominante e o dominado, o corpo exerce um papel-chave em relação à mudança cultural. É, sobretudo, a transferência de elementos relacionados ao corpo que causa mudanças radicais em autodefinições. Então, essas modificações terão impactos, tanto na forma como as pessoas envolvidas irão se perceber, como na forma como serão percebidas pelos outros. A mudança da identidade está sistematicamente associada com a mudança de padrões de comportamento que estão alinhados e adequados a essa nova identidade. 
$\mathrm{Na}$ fase atual das globalizações é bastante comum que os sistemas sociais, após terem sido alocados na periferia da cultura industrial, desistam de sua subsistência sustentável, e o resultado disso é que o contexto do sistema também se desestabiliza. A conexão causal da perda cultural e dos problemas ecológicos foi abordada pelo Programa das Nações Unidas para o Meio Ambiente (PNUMA) ${ }^{11}$.

Esses problemas também foram provocados em razão da indução de padrões de comportamento, o que se mostrou incompatível com esse novo contexto. A indústria cultural não apenas dá início ao problema, ela é também cada vez mais afetada pelas repercussões desses problemas. Dentro dos processos de globalização, autodefinições relacionadas ao corpo e, por isso, bastante relevantes para a identidade, não são apenas impostas às culturas indígenas pelos visitantes, mas também por intermédio da televisão, internet, revistas e outras mídias.

\section{A Cultura e o Corpo}

Até certo ponto, há alguma verdade na concepção de que culturas não industrializadas representam formas de viver, uma vez que já existiram em nossa cultura também. Um olhar mais cuidadoso sobre esse processo de mudança que se provocou na Europa evidencia que o espectro, que vai da cultura tradicional até a globalizada, correlaciona-se com a cobertura do corpo humano. Dentro dos processos históricos recentes, o corpo foi colocado sob um tabu e, ao mesmo tempo, como muitos aspectos do sistema, reinterpretado de uma forma voltada para a funcionalidade. Essa percepção funcionalizada do corpo levou à sexualização. Em culturas indígenas, a nudez não está associada com a sexualidade, como acontece com a cultura industrial recente. A percepção sexualizada, por parte da cultura industrial, leva inclusive a esforços para cobrirem os corpos dos índios, para que as visitas turísticas a vilarejos tradicionais não se tornem uma forma de turismo sexual. Por exemplo, clipes promocionais para visitação a aldeias indígenas no Brasil foram filmados depois que os seios das índias foram cobertos com sutiãs.

Desse modo, a exigência da cultura dominante para que a dominada atendesse aos padrões globais foi encorajar a sensação de vergonha e de desistência de sua autoapresentação autêntica. Os dominantes nem sequer consideram que os dominados não compartilham a interpretação sexual do corpo nu. Essa percepção específica é um problema da cultura industrial. Os dominantes, contudo, não questionam seu próprio ponto de vista; em vez disso, impõe o problema ao negar a definição de identidade indígena, sem se importar com as consequências dessa atitude. Entretanto o suposto problema está apenas nos olhos de quem vê; ele revela a forma sexualizada de pensar da cultura dominante.

A percepção sexualizada impede um encontro integrador, pois é um obstáculo para uma aceitação desprovida de preconceitos em relação aos outros. Afinal, essa visão turva é resultante dos padrões da cultura dominante de se cobrir o corpo. Para o ser humano, banir o corpo da vida cotidiana é uma privação, que leva à interpretação da pele nua em uma escala bem limitada que vai de "erótica" a "perversa". Para a pessoa globalizada, apenas a ideia de divergir da norma de cobrir o corpo é carregada de emoções. Ainda assim, uma visão turva como essa pode ser evitada. As percepções do corpo humano variam dentro da cultura in-

${ }^{11}$ Comunicado da UNEP/PNUMA para a imprensa, Nairóbi, 8 de fevereiro de 2001. 
dustrial. Sobretudo na Europa continental, a consciência em relação à saúde, muitas vezes, acompanha a presença da nudez em saunas, praias e outros locais, sem qualquer conotação sexual. Portanto, mesmo na cultura industrial, existe um segmento de pessoas que em geral vive de forma bastante consciente. Entre essas pessoas, certamente há algumas com profundo interesse em culturas indígenas, com aceitação verdadeira e um desejo de se integrar ao contexto tradicional quando exposta a ele.

Homens e mulheres estão afetados em níveis diferentes com o tabu da cultura industrial em relação ao corpo humano. Quando os índios, arrancados de sua cultura tribal, têm de trabalhar em plantações ou portos, eles geralmente trocam sua tanga por um short. A área do corpo coberta permanece a mesma. Para as índias que vão trabalhar fora de sua cultura nativa, a situação é bem diferente, uma vez que, no estágio atual da globalização, elas estão sujeitas à imposição de um tabu relacionado ao seio feminino - o que acrescenta mais uma área do corpo tabu. Esse fenômeno ocorre globalmente com tanta consistência que passa a ser um indicador, o que nos permite acessar o estado de uma cultura da perspectiva da psicologia cultural. Em sociedades não globalizadas, o seio não está associado com a sexualidade, mas com maternidade, nutrição, sensação de segurança e outros aspectos afetuosos. Destruir a autoconfiança feminina, impondo vergonha a algo que durante milênios na história humana teve uma conotação positiva emocional e respeitosa, é um ponto-chave na desestabilização de culturas indígenas. Certamente, a maioria das mulheres turistas não percebem as consequências quando sem consciência agem como modelo, promovendo o tabu dos seios para as mulheres indígenas.

Historicamente, o tabu do seio na cultura industrial é apenas um fenômeno recente. Como afirmou Hobsbawm (1978), a reestruturação da sociedade durante a Revolução Industrial teve um impacto forte na conceitualização do corpo. O ser humano tornou-se um componente integrante dos processos de produção cada vez mais mecanizados. Nessa fase da história, aspectos da qualidade de vida eram considerados bastante irrelevantes. Exigiase que os homens sacrificassem o máximo de seu tempo e força. Vegetando em quintais, o único propósito de suas famílias era manter o sistema funcionando e fornecer mão de obra. Durante esse tempo, a conceitualização do corpo humano passou por uma mudança drástica. Ainda de acordo com Hobsbawm (1978), até esse momento, o corpo feminino era visto de uma maneira bastante positiva, embora não sexualizada, como era tematizado em contextos alegóricos. Entretanto, naquele período, durante a Revolução Industrial, ele foi desalojado pelo corpo do trabalhador masculino. Assim como logo anteriormente em " $L a$ liberté guidant le peuple", de Delacroix, Marianne, a efígie Francesa, se encontrava à beira da barricada com um dos seios despidos, agora eram os homens que lá estavam dessa maneira. Destse momento em diante, o corpo feminino tornou-se cada vez mais um tabu e, portanto, passou a ser coberto. De uma perspectiva psicológica, essa cobertura do corpo é a implementação de uma desemocionalização. Por outro lado, o corpo masculino tornou-se publicamente funcionalizado, pois representava o trabalhador herói.

Durante esse período de industrialização, as roupas de repente se tornaram cada vez mais disponíveis, e os próprios trabalhadores e suas famílias eram os principais consumidores. Ter roupas, por um lado, tinha a função de assinalar prestígio; mas, por outro lado, cobrir o corpo era um ato irracional que, desde o início, implicava uma perda de valores envolta em funções psicológicas profundas. 
Na cultura globalizada de hoje, o conceito corporal e a forma como o corpo é tratado não é algo apropriado para nossa espécie; o corpo humano está alienado da natureza. Agora, o corpo está sujeito a conotações vergonhosas, seu valor está atrelado a aspectos funcionais e comerciais que privam mulheres de uma dignidade que elas tinham em sociedades pré-industriais. Na periferia da cultura industrial, nas quais as sociedades indígenas estão sendo anexadas ao sistema globalizado, a situação pode ser comparada à da industrialização europeia de cerca de 1800. A autonomia indígena continuará sem ter chance alguma enquanto as identidades indígenas continuarem sendo eliminadas pela indução externa de formas globais de autoapresentação corporal.

\section{Argumentações Dominantes}

É evidente que há uma resistência irracional por parte da cultura dominante contra a aceitação das culturas indígenas ou até a uma integração com ela durante uma visita. Qualquer comportamento, que é diferente daquele que a pessoa internalizou ao longo de sua própria socialização, provoca ansiedade. A retórica dominante não é muito objetiva, mas é eficaz, e é caracterizada pelo escárnio sobre a ideia de integração a um ambiente indígena. Isso é psicologicamente explicável como mecanismo de defesa à ansiedade em relação ao desconhecido. Quando o escárnio em si é feito um assunto da discussão, então a cultura dominante argumenta que o andamento da globalização não pode ser interrompido, não se pode mudar a história. Porém o interessante é que o curso da história mostra que esses argumentos estão errados, por exemplo: no sul da África, viu-se a diminuição da cultura indígena autêntica durante o período do Apartheid. Qualquer tentativa de restaurar essas culturas resultaria em zombaria com os seguintes recados: "o trem já partiu da estação", "não se pode voltar no tempo" etc. Ainda assim, após o fim do Apartheid, a cultura tradicional tem sido reconstruída no nível da semiótica corporal, em termos de autoapresentação relevante para a identidade, sobretudo na região Zulu. Hoje, festividades tradicionais novamente são celebradas por dezenas de milhares de pessoas com aparência corporal autêntica.

Quando se discute com a cultura dominante, é útil destacar que qualquer integração durante uma visita a uma cultura indígena é uma forma de demonstrar respeito em relação a esta, como usar um quipá na sinagoga ou entrar em uma mesquita sem sapatos.

\section{Treinamento e Educação ${ }^{12}$}

Treinar estudantes para trabalho de campo em contextos indígenas pode colidir com os padrões de contextos globalizados. Um grande obstáculo em relação a esse assunto é a associação da nudez com a sexualidade. Essa associação é um fenômeno moderno. A nudez, como tal, jamais fora equiparada à sexualidade ao longo da história da humanidade. A interpretação principalmente sexual da nudez é resultado de normas para cobrir o corpo que se espalharam desde o começo da Revolução Industrial. Em alguns lugares, essas normas foram estabelecidas há algumas gerações, enquanto alguns lugares indígenas ainda não foram tocados. Contudo uma vez que a educação acadêmica faz parte do mundo globalizado,

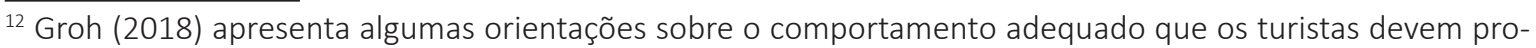
duzir em contextos indígenas.
} 
as precauções precisam ser tomadas para evitar a colisão entre o comportamento integrador, que é apropriado a contextos indígenas, e certos padrões globais. Em primeiro lugar, somente essas pessoas deveriam ter permissão para participar de pesquisas em contextos indígenas tradicionais, que não têm dificuldades nem reservas se comportar "normal" em situações de nudez. Para filtrar pessoas não qualificadas para tal trabalho, é preciso que haja uma parte prática no treinamento com simulações de campo específicas. Nessas simulações, os estagiários devem provar sua capacidade de se comunicarem normalmente e levarem adiante a coleta de dados como se estivessem naqueles locais de verdade. O ambiente para esse treinamento prático deve ser absolutamente seguro e vigiado para evitar qualquer tipo de abuso ${ }^{13}$. Como fazemos esses seminários há muitos anos, percebemos que os alunos que foram bem-sucedidos nesse treinamento estavam aptos para participar de excursões a culturas indígenas, e que se pode esperar um comportamento adequado deles quando presentes nessas comunidades.

Neste treinamento, são esperados alguns obstáculos, uma vez que os alunos foram socializados em um contexto global e, portanto, podem, a princípio, rejeitar automaticamente os padrões tradicionais da cultura indígena, dirigidos pelo afeto, mas muitas vezes racionalizados de forma repercussiva com meras projeções, atribuições e interpretações. Contudo a lógica pode ser restaurada quando os problemas e inter-relações são reflexos de um meta-nível. Ao se fazer isso, é necessário destacar que conotações sexuais da nudez, como as encontradas na cultura globalizada, não são aplicáveis a culturas indígenas. Assim como os teóricos da Encarnação Social (Barsalou, Niedenthal, Barbey, \& Ruppert, 2003; Niedenthal, Barsalou, Winkielman, Krauth-Gruber, \& Ric, 2005) deixaram claro, não é apenas o estado psicológico que se reflete no estado corporal, mas também o inverso: o estado corporal influencia decisivamente o estado psicológico. Os alunos geralmente confirmam que, após o treinamento, eles passaram a ter uma forma completamente nova de ver o mundo.

Nesses seminários, também se ressalta que, em relação a aspectos metodológicos de pesquisa relacionada a cultura, não faria sentido influenciar uma cultura que será estudada. Quando temos em mente os mecanismos das definições de identidade cultural e suas desestabilizações por parte da cultura dominante, então, consequentemente, temos que evitar a importação de elementos culturais de relevância para a identidade nas culturas tradicionais. Isso significa que temos de nos adaptar à aparência tradicional e nos abster de velar nossos corpos como estamos acostumados a fazer no ambiente globalizado.

Quando os alunos decidem fazer parte desse treinamento, com consentimento informado, completo e livre, eles então são solicitados a aplicaram as novas habilidades sem compromisso. Um cuidado especial deve ser tomado para não importar ou acrescentar o tabu dos seios a culturas indígenas por ser um efeito particularmente desestabilizador. Portanto sutiãs ou qualquer outra cobertura que comunique que as mulheres deveriam ter vergonha dos seios devem ser severamente evitados.

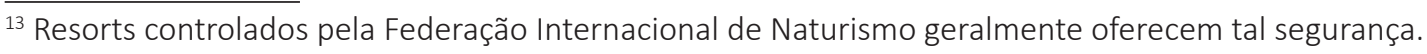




\section{Autonomia Cultural Indígena}

Para proteger e amparar as culturas indígenas, é absolutamente necessário que a cultura dominante respeite os povos indígenas. É de responsabilidade da cultura dominante não introduzir sinais de dominância nas culturas indígenas, evitando, assim, futuras desestabilizações. A integração a uma cultura indígena não significa que o visitante precise passar por modificações corporais com cicatrizes decorativas, perfurações ou algo semelhante. Na verdade, significa que redefinições corporais, por meio da indução ou reforço das vestimentas, não devem ser induzidas. É importante ter em mente que: 1) existem efeitos de dominância entre a cultura industrial e a indígena; 2) modificações de comportamento são determinadas pelo desequilíbrio da dominância; 3) representantes da cultura industrial são sempre modelos; e 4) modificações do conceito corporal afetam profundamente a identidade.

De qualquer maneira, os visitantes podem neutralizar essas desestabilizações direcionando sua aparência corporal para os padrões de aparência corporal culturalmente específicos, tradicionais e autênticos. Se a cultura indígena já estiver desestabilizada, os visitantes dominantes, como representantes da cultura destrutiva, devem realizar um trabalho de resgate reintroduzindo e encorajando a aparência tradicional, fortalecendo assim a autoconfiança cultural dessas pessoas com essa atitude de reconhecimento e confirmação. A intervenção, com objetivo de manter a cultura indígena, precisa concentrar-se no corpo, porque é a comunicação visual da autoapresentação corporal que induz à desestabilização. Primeiramente, as identidades individuais das pessoas que compõem a cultura indígena, são desestabilizadas. Depois, a desestabilização das identidades de seus membros eventualmente leva à morte dessa cultura.

Todos esses mecanismos, tantos de desestabilização como os de neutralização da desestabilização, são fenômenos da comunicação visual. A intervenção deve ser restrita a essa área, porque a liberdade da troca intelectual deve permanecer intocada. Porém, a troca intelectual só poderá ser livre se a comunicação for em base da aceitação, e não da dominação. E a comunicação da aceitação ocorre no plano visual. A apresentação do corpo comunica a afiliação, o pertencimento de uma pessoa, o que, por sua vez, implica, para o bem, aceitação ou, para pior, rejeição.

\section{Conclusão e Perspectivas}

A cultura industrial global exerce uma dominância extrema sobre as culturas indígenas tradicionais. Pessoas da cultura dominada que são expostas à cultura dominante vivenciam fortes sensações de inferioridade, que elas tentam evitar adaptando sua autoapresentação à cultura dominante. Ao usarem roupas, elas se definem como globalizadas. Essa adoção implica uma mudança de uma identidade tradicional para uma moderna. Uma vez que a cultura é feita de pessoas, a anulação das identidades tradicionais acarreta a morte da cultura tradicional. Nós, como representantes da cultura global, devemos observar normas éticas e, assim, não fazermos as pessoas se sentirem inferiores; certamente não devemos desestabilizar nem muito menos destruir uma cultura. Em vez disso, devemos transformar a aceitação e o respeito mútuos em ações.

Desde 2007, a Declaração das Nações Unidas sobre os Direitos dos Povos Indígenas está em vigor como parte do Direito Internacional. Todos devemos respeitar a lei e, portanto, evitar qualquer ação que possa resultar na desestabilização de uma cultura indígena. 
Visto que a consequente integração ao contexto tradicional exige que não se use roupas durante a permanência temporária, qualquer um que não seja capaz de se comportar normalmente sob tais circunstâncias não deve entrar em um território de cultura indígena. Não seria aceitável fazer compromissos que ocasionassem a possibilidade de desestabilização da cultura indígena apenas porque uma pessoa da cultura dominante não está disposta a lidar com seus próprios problemas.

A conotação negativa da nudez indígena apenas existe nos olhos de quem a vê; não há razão para impô-la nas culturas em questão. Devemos estar muito cientes de que, com a eliminação de identidades indígenas, outros processos que contribuem para problemas ecológicos globais, entre outros, são provocados.

Existem várias razões convincentes para encontros minimamente invasivos, integrativos e imersivos com povos indígenas e, quando possível, para o trabalho de resgate, 'rescue work', oportunizando, por exemplo, devolver-lhes a sua nudez, que foi roubada e ajudando a revitalizar sua cultura.

Como parte da cultura dominante, devemos ter ciência de nossas responsabilidades. Devemos fazer uso de nossos meios para pesquisar os processos subjacentes da mudança cultural e garantirmos que nossas abordagens sejam culturalmente sustentáveis. Um discurso racional sobre as interdependências complexas, junto com a determinação sincera para neutralizar a perda de culturas, poderia dar esperança de que esses processos destrutivos serão interrompidos.

\section{Referências}

Asch, S. E. (1951). Effects of group pressure upon the modification and distortion of judgement. In H. S. Guetzkow (Ed.), Groups, leadership, and men. Research in human relations. Reports on research sponsored by the Human Relations and Morale Branch of the Office of Naval Research, 1945-1950 (pp. 177-190). Reissued, Pittsburgh: Carnegie Press.

Barsalou, L. W., Niedenthal, P. M., Barbey, A. K., \& Ruppert, J. A. (2003). Social embodiment. In B. Ross (Ed.), The psychology of learning and motivation (Vol. 43, pp. 43-92). San Diego: Academic Press.

Bartlett, S. F. C. (1932). Remembering: A study in experimental and social psychology. London: Cambridge University Press.

Burris, C. T., \& Rempel, J. K. (2004). It's the end of the world as we know it: Threat and the spatial-symbolic self. Journal of Personality and Social Psychology, 86(1), 19-42.

Declaração das Nações Unidas sobre os Direitos dos Povos Indígenas. 2007. Disponível em https://www.un.org/esa/socdev/unpfii/documents/DRIPS_pt.pdf

Festinger, L. (1957). A Theory of Cognitive Dissonance. Stanford: University Press.

Freeman, D. (1983). Margaret Mead and Samoa: The making and unmaking of an anthropological myth. Cambridge/Massachusetts \& London: Harvard University Press.

Freud, S. (1913). Totem und tabu: Einige übereinstimmungen im seelenleben der wilden und der neurotiker. Frankfurt: Fischer.

Frey, D. (1981). Informationssuche und informationsbewertung bei entscheidungen. Bern: Huber. 
Gallagher, S. (2005). How the body shapes the mind. Oxford: Oxford University Press. Gibbons, A. (1992). Rain forest diet: You are what you eat. New York: Science.

Goffman, E. (2009). A representação do EU na vida cotidiana (17a ed.). Petrópolis, RJ: Vozes. Groh, A. (1993a). Ein Ansatz zur mathematischen Modellierung kulturellen Transfers. Grundlagenforschung Kybernetik und Geisteswissenschaften, (34)3, 110-118.

Groh, A. (1993b). Formal-informationswissenschaftliche Überlegungen zu den Effekten kultureller Dominanz auf die Stabilität von Symbolsystemen. Grundlagenforschung Kybernetik und Geisteswissenschaften, (34)4, 172-182.

Groh, A. (2005). Minimalinvasives reisen. Integrative begegnungen mit indigenen. In: A. Groh (Ed.), Bewegung, akademische perspektiven auf reisen und ortswechsel. Berlin: Weidler.

Groh, A. (2006). Globalisation and indigenous identity. Psychopathologie Africaine, 33(1), 33-47.

Groh, A. (2007). La globalización: una amenaza para la diversidad cultural. In: FAPCl (Ed.), Salud y diversidad cultural en el mundo (pp. 47-70). Barcelona: $\mathrm{FAPCl}$.

Groh, A. (2012). Tourism and indigenous communities: Implementing policies of sustainable management. In E. A. Fongwa (Ed.), Sustainability assessment: Practice, method and emerging socio-cultural issues for sustainable development (pp. 168-183). Saarbrücken: SVH.

Groh, A. (2018). Research methods in indigenous contexts. New York: Springer.

Heine, A. (1991). Lebensraum regenwald: Forschungsreise durch ein labiles Ökosystem. Manuscript of a Deutschlandfunk broadcasting of 16 Jan. 1991.

Hill, T. L. (1996). The problem with non-nudists. Society / Société: Newsletter of the Canadian Sociology and Anthropology Association, 20, 23-25.

Hobsbawm, E. J. (1978). Sexe, symboles, vetements et socialisme. Actes de la Recherche en Sciences Sociales, 23, 2-18.

Kohonen, T. (1988). Self-organisation and associative memory. Berlin: Springer.

Kummer, W. (1990). Sprache und kulturelle Identität. In E. J. Dittrich, \& F. O. Radtke (Eds.), Ethnizität. Wissenschaft und Minderheiten (pp. 265-275.). Opladen: Westdeutscher Verlag.

Lévi-Strauss, C. (1973). Das wilde Denken. Frankfurt: Suhrkamp Taschenbuch. (Publicado originalmente: La pensée sauvage. Paris: Plon, 1962).

Lewin, K. (1951). Field theory in social sciences. New York: Harper \& Row.

Mead, G. H. (1934). Mind, self, and society. Chicago: University of Chicago Press.

Mead, M. (1928). Coming of age in Samoa. Harmondsworth: Penguin.

Milgram, S. (1974). Obedience to authority; an experimental view. New York: Harper \& Row. Mummendey, H. D. (1990). Psychologie der Selbstdarstellung. Göttingen, Toronto, Zürich: Hogrefe.

Mummendey, H. D., \& Bolten, H. G. (1985). Die Impression-Management-Theorie. In D. Frey, \& M. Irle (Eds.). Theorien der Sozialpsychologie: Motivations- und Informationsverarbeitungstheorien (Vol. 3, pp. 57-77). Toronto: Verlag Hans Huber.

Niedenthal, P. M., Barsalou, L. W., Winkielman, P., Krauth-Gruber, S., \& Ric, F. (2005). Embodiment in attitudes, social perception, and emotion. Personality and Social Psychology Review, (9)3, 184-211. 
Palm, G. (1982). Neural assemblies. An alternative approach to artificial intelligence. Berlin, Heidelberg: Springer.

Posner, R. (1989). What is culture? Toward a semiotic explication of anthropological concepts. In W. A. Koch (Ed.). The nature of culture: Proceedings of the international and interdisciplinary symposium, October 7-11, 1986 in Bochum (pp. 240-295). Bochum: Brockmeyer.

Snow, D. A. (2001). Collective identity and expressive forms. Center for the Study of Democracy, paper 01'07. Disponível em https://lingcult.files.wordpress.com/2008/08/david-snowidentidade-coletiva.pdf

West, K. (2017). Naked and unashamed: Investigations and applications of the effects of naturist activities on body image, self-esteem, and life satisfaction. Journal of Happiness Studies, 17, 1-21. doi: 10.1007/s10902-017-9846-1.

West, S. G., \& Wicklund, R. A. (1985). Einführung in sozialpsychologisches Denken. Weinheim and Basel: Beltz.

Wicklund, R. A., \& Gollwitzer, P. M. (1982). Symbolic self-completion. Hillsdale: Lawrence Erlbaum.

Recebido: 29/11/2018

Última revisão: 07/02/2019

Aceite final: $17 / 03 / 2019$

\section{Sobre o autor:}

Arnold Groh - Chefe da unidade de pesquisa de Análise Estrutural de Sistemas Culturais, em status consultivo especial junto ao Conselho Econômico e Social das Nações Unidas. Psicólogo, linguista, acadêmico literário e semiólogo. Ensina como professor particular na Universidade Técnica de Berlim. Ele também leciona na Universidade Livre de Berlim, na Universidade Humboldt, na Universidade das Artes, bem como em várias universidades privadas e instituições públicas. Fez extensa pesquisa de campo no Sudeste Asiático, África e América Latina. Entre suas publicações estão os manuais sobre "Métodos de Pesquisa em Contextos Indígenas" (Springer, 2018) e sobre "Teorias da Cultura" (Routledge, junho de 2019). E-mail: arnold.groh@tu-berlin.de, Orcid: http://orcid.org/0000-0001-6001-4816 